\title{
BMJ Open Dietary intake and sources of sodium and potassium among Australian schoolchildren: results from the cross- sectional Salt and Other Nutrients in Children (SONIC) study
}

Carley A Grimes, ${ }^{1}$ Lynn J Riddell, ${ }^{1}$ Karen J Campbell, ${ }^{1}$ Kelsey Beckford, ${ }^{1}$ Janet R Baxter, ${ }^{1}$ Feng $\mathrm{J} \mathrm{He},{ }^{2}$ Caryl A Nowson ${ }^{1}$

To cite: Grimes CA, Riddell LJ, Campbell KJ, et al. Dietary intake and sources of sodium and potassium among Australian schoolchildren: results from the cross-sectional Salt and Other Nutrients in Children (SONIC) study. BMJ Open 2017;7:e016639. doi:10.1136/ bmjopen-2017-016639

- Prepublication history and additional material for this paper are available online. To view these files, please visit the journal online (http://dx.doi. org/10.1136/bmjopen-2017016639).

Received 5 March 2017 Accepted 21 July 2017

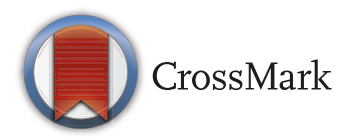

${ }^{1}$ Institute for Physical Activity and Nutrition, Deakin University, Geelong, Australia

${ }^{2}$ Wolfson Institute of Preventative Medicine, Barts and The London School of Medicine and Dentistry, Queen Mary University of London, London, UK

Correspondence to Dr Carley A Grimes; carley.grimes@deakin.edu.au

\section{ABSTRACT}

Objectives To examine sodium and potassium urinary excretion by socioeconomic status (SES), discretionary salt use habits and dietary sources of sodium and potassium in a sample of Australian schoolchildren.

Design Cross-sectional study.

Setting Primary schools located in Victoria, Australia. Participants 666 of 780 children aged $4-12$ years who participated in the Salt and Other Nutrients in Children study returned a complete 24-hour urine collection. Primary and secondary outcome measures 24-hour urine collection for the measurement of sodium and potassium excretion and 24-hour dietary recall for the assessment of food sources. Parent and child reported use of discretionary salt. SES defined by parental highest level of education.

Results Participants were 9.3 years ( $95 \% \mathrm{Cl} 9.0$ to 9.6$)$ of age and $55 \%$ were boys. Mean urinary sodium and potassium excretion was 103 (95\% Cl 99 to 108) mmol/ day (salt equivalent $6.1 \mathrm{~g} /$ day) and 47 (95\% Cl 45 to 49) $\mathrm{mmol} /$ day, respectively. Mean molar Na:K ratio was 2.4 (95\% Cl 2.3 to 2.5$)$. $72 \%$ of children exceeded the agespecific upper level for sodium intake. After adjustment for age, sex and day of urine collection, children from a low socioeconomic background excreted $10.0(95 \% \mathrm{Cl}$ 17.8 to 2.1$) \mathrm{mmol} /$ day more sodium than those of high socioeconomic background $(p=0.04)$. The major sources of sodium were bread (14.8\%), mixed cereal-based dishes $(9.9 \%)$ and processed meat $(8.5 \%)$. The major sources of potassium were dairy milk (11.5\%), potatoes $(7.1 \%)$ and fruit/vegetable juice (5.4\%). Core foods provided $55.3 \%$ of dietary sodium and $75.5 \%$ of potassium while discretionary foods provided $44.7 \%$ and $24.5 \%$, respectively.

Conclusions For most children, sodium intake exceeds dietary recommendations and there is some indication that children of lower socioeconomic background have the highest intakes. Children are consuming about two times more sodium than potassium. To improve sodium and potassium intakes in schoolchildren, product reformulation of lower salt core foods combined with strategies that seek to reduce the consumption of discretionary foods are required.
Strengths and limitations of this study

- This is the largest Australian study to use urinary biomarkers to objectively measure sodium and potassium intakes among schoolchildren.

- For the first time, the contribution of sodium and potassium from core and discretionary foods among Australian schoolchildren is described, and this information can be used to inform public health policy.

- The convenience sample and low response rate limit the generalisability of findings to the wider paediatric Australian population.

\section{INTRODUCTION}

In adults, a diet low in sodium and high in potassium can reduce blood pressure ${ }^{12}$ and the risk of cardiovascular disease. ${ }^{34}$ A similar relationship between sodium, potassium and blood pressure exists among children. Meta-analyses have shown that reductions in dietary sodium lead to modest reductions in childhood blood pressure, ${ }^{25}$ and longitudinal studies have found that a higher intake of potassium during childhood was associated with lower systolic blood pressure in adolescence. ${ }^{67}$ A lower ratio of sodium to potassium during childhood also appears to protect against rises in blood pressure. ${ }^{6-8}$ Blood pressure tracks over the life course, ${ }^{9}$ with raised levels in childhood increasing the risk of high blood pressure later in life ${ }^{10}$ as well as contributing to early vascular damage ${ }^{11}{ }^{12}$ As a means to maintain healthy blood pressure levels over the life course, there is strong support for initiatives that seek to reduce sodium intake among children. ${ }^{13}$ Other concerns of excess dietary sodium during childhood include the development of taste preferences that favour salty foods. ${ }^{14}$ 
As part of the global targets for the prevention and control of non-communicable diseases, ${ }^{15}$ Australia has committed to a $30 \%$ reduction in population salt intake. While there have been some efforts to reduce salt intake, to date there has been no nationally orchestrated salt reduction policy with the inclusion of robust monitoring measures. ${ }^{15}$ Recently, work has progressed at the State level, with the 2015 launch of the 'State of Salt: The Case for Salt Reduction in Victoria'. ${ }^{15}$ This initiative seeks to reduce salt intake among Victorian adults and children by supporting stronger action on salt by consumers, the food industry and government. ${ }^{16}$ To monitor progress, it is important to assess salt intake in different population groups.

Twenty-four-hour urinary sodium excretion is considered the most accurate method to measure salt intake. ${ }^{17}$ Few Australian studies have used this methodology. ${ }^{18} 19$ National estimates for sodium and potassium are based on 24-hour dietary recall methods. ${ }^{20}$ Globally, there has been an increase in the number of studies utilising 24-hour urinary sodium and potassium excretion for the assessment of salt and potassium intake in children. ${ }^{21-25} \mathrm{In}$ order to evaluate public health efforts that seek to reduce salt intake among Australian children, it is important that an accurate measure of total salt intake (ie, including both food and discretionary sources) is available. Importantly, this should be combined with information on food sources of sodium, including the contribution of sodium from core and discretionary foods. This information can help to inform and evaluate strategies that seek to improve dietary intakes. For example, in the case of lowering sodium intake, should efforts be focused on product reformulation of lower sodium foods or are strategies to reduce the consumption of discretionary foods required? The primary aim of this study was to determine sodium (ie, salt) intake using 24-hour urinary excretion in a sample of Victorian schoolchildren aged 4-12 years. As the ratio of sodium to potassium is related to health outcomes, we also determined potassium intake and the sodium to potassium ratio. Secondary aims included (1) examination of differences in electrolyte excretion and 'discretionary' salt use habits by demographic characteristics (age, sex, socioeconomic status), and (2) identification of the dietary sources of sodium and potassium, including the contribution from 'core' and 'discretionary' foods as defined by the Australian Dietary Guidelines.

\section{METHODS}

Data were collected from June 2010 to May 2013 as part of the cross-sectional Salt and Other Nutrient Intakes in Children study. The study methodology ${ }^{26}$ and preliminary findings ${ }^{18}$ have been described. Ethics approval was obtained by the Deakin University Human Research Ethics Committee (project number EC62-2009) and the Victorian Department of Education and Early Childhood Development (2011_001151). Of the 509 government and non-government schools invited to participate, 56 schools
$(11 \%)$ agreed. Within participating schools, consent was obtained from 852 children (response rate $=6 \%$ ); 41 children withdrew from the study and children who did not agree to attend an off school campus data collection day $(n=25)$ or who were aged $>13$ years $(n=6)$ were excluded, leaving 780 participants. ${ }^{26}$ Written parental/ guardian consent and child assent were obtained for all participants.

\section{Measures}

Demographic characteristics and 'discretionary' salt use

The primary carer completed a questionnaire assessing child age, sex, parental level of education and 'discretionary' salt use. Discretionary salt use included salt added at the table or during cooking and was assessed via four questions. ${ }^{26}$ Parents were asked the following: "Do you add salt during cooking?", "Do you place a salt shaker on your table at meal times?" and "Does your child add salt to their meal at the table or during sandwich preparation?". Children were asked "Do you add salt to your meal at the table?". For all questions, responses included 'yes, usually', 'yes, sometimes', 'no' or 'don't know'. Responses for 'don't know' have been excluded from analyses.' The highest level of education obtained by the parent was used to define socioeconomic status (SES) of participants: (1) low SES includes those with some or no level of high school education, (2) mid SES includes those with a technical/trade certificate and (3) high SES includes those with a university/tertiary qualification. Information on parental educational attainment was collected retrospectively in $\mathrm{n}=254$ children. ${ }^{26}$ Within this group of 254 children, data could only be obtained in 160 (63\%) children.

\section{Twenty-four-hour urine collection}

Children could opt to commence the 24-hour urine collection on either a school day or non-school day (ie, weekends, public holidays and school holidays); detailed procedures are described elsewhere. ${ }^{26}$ Urine samples were analysed at an accredited commercial pathology laboratory (Dorevitch Pathology, Melbourne, Australia). If the duration of the collection was not exactly 24 hours, but within 20-28hours, urinary electrolytes, creatinine and total volume were standardised to a 24-hour period (ie, (24hours/urine duration (hours)) ×urinary measure). Urine samples were considered incomplete if collection time was $<20$ hours or $>28$ hours $(n=5)$, total volume was $<300 \mathrm{~mL}(\mathrm{n}=37)$, the participant reported missing $>1$ collection $(n=14)$ or urinary creatinine excretion was less than $0.1 \mathrm{mmol} / \mathrm{kg}$ body weight/ day $(\mathrm{n}=69),{ }^{26}$ and one extreme outlier $>8 \mathrm{SD}$ from the mean for sodium was excluded leaving a final sample of 666 .

\section{Twenty-four-hour dietary recall}

One face-to-face three-pass 24-hour dietary recall was completed in a subsample of children aged $\geq 8$ years $(n=498) .{ }^{26}$ Implausible intakes of energy were assessed by comparing each participant's ratio of reported energy intake to estimated basal metabolic rate (EI:estBMR), 
to the paediatric adjusted Goldberg cut-off value. ${ }^{27}$ Age-specific and sex-specific Goldberg cut-off values were determined using child-specific light physical activity levels $^{28}$ and revised estimates ${ }^{29}$ for the coefficient of variation $(\mathrm{CV})$ in energy intake $\left(\mathrm{CV}_{\text {wEI }} 23 \%\right)$, repeated BMR measurements $\left(\mathrm{CV}_{\mathrm{wB}} 8.5 \%\right)$ and variation in PAL $\left(\mathrm{CV}_{\text {tp }} 15 \%\right)$. On this basis, participants $(\mathrm{n}=32,5.8 \%)$ with an EI:estBMR ratio less than 0.87 for boys aged $8-12$ years and 0.84 for girls aged 8-12 years were classified as a low energy reporter and excluded. Children with energy $>4$ SDs $(n=3)$ more than the mean (ie, $>18867$ ) were excluded, leaving a final sample of 517. Logistically, it was not possible to concurrently collect 24-hour dietary recalls alongside the 24-hour urine collection. Of the 517 children with valid 24-hour dietary recall data, $\mathrm{n}=464$ also had a complete 24-hour urine collection. Among these children, 90\% ( $\mathrm{n}=417)$ completed the 24-hour dietary recall and 24-hour urine collection within a week of one another.

Reported food and beverage intake was converted into nutrient intakes using the Australian food composition database AUSNUT 2011-2013 ${ }^{30}$ and nutrient analysis program FoodWorks V.8 (Xyris). This is the most recent Australian food composition database that was made available via the FoodWorks analytical program in September 2015 and is an update from our previous report. ${ }^{31}$ Intakes of energy (MJ/day), sodium (mg/ day), sodium density (mg/MJ) and potassium (mg/ day) are reported. The contribution of sodium and potassium from food groups was determined using the AUSNUT 2011-2013 Food Classification System, which groups individual food items into major, submajor and minor food groups. Individual foods consumed were coded as either a core or discretionary food, according to the Australian Guide to Healthy Eating classification system. ${ }^{32}{ }^{33}$ Core foods include those found within the five food groups, for example, (1) grain (cereal) foods; (2) vegetables and legumes/beans; (3) fruit; (4) milk, yoghurt, cheese and/or alternatives; and (5) lean meats and poultry, fish, eggs, tofu, nuts and seeds and legumes/beans, as well as water and polyunsaturated and monounsaturated spreads and oils. ${ }^{33}$ Discretionary foods do not fall within the five food groups; many are high in kilojoules, saturated fat, added sugars, added salt or alcohol. These foods are not necessary for a healthy dietary pattern and should only be consumed in occasional small amounts. ${ }^{33}$

\section{Anthropometry}

Height and weight were measured using standard protocols by trained researchers. ${ }^{26}$

Body mass index (BMI) values were converted to age-adjusted and sex-adjusted BMI z-scores using the 2000 US Centers for Disease Control and Prevention growth charts. ${ }^{34}{ }^{35}$ Participants were grouped into weight categories using the International Obesity Taskforce BMI reference cut-offs for children. ${ }^{3637}$

\section{Statistical analysis}

Descriptive statistics mean $\pm \mathrm{SE}$ and $\mathrm{n}(\%)$ were used to describe continuous and categorical variables. The molecular weights of sodium $(23 \mathrm{~g} / \mathrm{mol})$ and sodium chloride $(58.5 \mathrm{~g} / \mathrm{mol})$ were used to convert millimoles of sodium to milligrams. The proportion of children with a sodium excretion exceeding the age-specific upper level (UL) for sodium intake (ie, $1000 \mathrm{mg}$ /day for children aged 4-8 years and $2000 \mathrm{mg} /$ day for children aged 9-12 years) ${ }^{38}$ was calculated. Linear regression, with adjustment for school cluster, was used to compare differences in electrolyte excretion by sex, age group and SES. We present unadjusted models (model 1) as well as models adjusted for covariates, that is, model 2 adjusted for age, sex and day of urine collection (ie, school day or non-school day) and model 3 adjusted for model 2+BMI z-score. For the analysis related to socioeconomic background, SES group was entered as an indicator variable into the model with the low SES group acting as the reference group. Furthermore, as this model included multiple comparisons between SES subgroups, the Bonferroni correction for $p$ values was also reported. Logistic regression, with adjustment for school cluster, was used to assess differences in 'discretionary' salt use habits by sociodemographic characteristics (eg, sex, age group and SES). The population proportion method was used to calculate the contribution of sodium and potassium from food groups, as well as 'core' and 'discretionary' foods. ${ }^{39}$ Food groups that contributed to $\geq 1 \%$ of daily intakes are reported.

\section{RESULTS}

Of the 666 children with complete urine collections, just over half were boys, the average age was $9.3 \pm 0.1$ years and about a third were of a high socioeconomic background (online supplementary table 1 ).

\section{Twenty-four-hour urinary electrolyte excretion}

Mean urinary sodium excretion was $103 \mathrm{mmol} /$ day, equivalent to $6.1 \mathrm{~g} /$ day of salt (table 1 ). Sodium excretion was significantly greater among boys and among older children, aged 9-12 years (table 1). Seventy-eight percent and $67 \%$ of children aged 4-8 years and 9-13 years exceeded the age-specific UL for sodium intake. Sodium excretion was significantly greater on non-school days $(110.4 \pm 2.5 \mathrm{mmol} /$ day, salt equivalent $6.5 \pm 0.1 \mathrm{~g}$ / day) compared with school days $(95.7 \pm 3.0 \mathrm{mmol} /$ day, salt $5.6 \pm 0.2 \mathrm{~g} /$ day $)(\mathrm{p}<0.001)$. Adjusted for age and sex, this difference remained whereby sodium excretion was $16.4 \pm 3.3$ (95\% CI 9.8 to 23.1$) \mathrm{mmol} /$ day $(1.0 \mathrm{~g} /$ day salt) greater on non-school days. With additional adjustment for BMI z-score, this difference remained whereby sodium exertion was $17.3 \pm 3.2$ (95\% CI 10.8 to 23.8$) \mathrm{mmol} /$ day greater on non-school days. Further adjustment for SES among children with this data $(\mathrm{n}=570)$ did not alter this association. Mean urinary potassium excretion was $47 \mathrm{mmol} /$ day and, like sodium, potassium excretion was significantly greater among boys and older children 
Table 1 Twenty-four-hour urinary electrolyte excretion by age group and sex among participants aged 4-12 years*

\begin{tabular}{|c|c|c|c|c|c|c|c|c|c|}
\hline \multirow[b]{2}{*}{ Urinary marker } & \multicolumn{3}{|c|}{ 4-12 years } & \multicolumn{3}{|c|}{ 4-8years } & \multicolumn{3}{|c|}{ 9-12 years } \\
\hline & All & Boys & Girls & All & Boyst & Girls & All & Boyst & Girls \\
\hline No of participants & 666 & 365 & 301 & 283 & 159 & 124 & 383 & 206 & 177 \\
\hline Sodium (mmol/day) & $103 \pm 2$ & $109 \pm 3 \ddagger$ & $97 \pm 3$ & $90 \pm 2 \S$ & $94 \pm 2 \ddagger$ & $85 \pm 3$ & $113 \pm 3$ & $120 \pm 4 \ddagger$ & $105 \pm 3$ \\
\hline Salt equivalent (g/day) & $6.1 \pm 0.1$ & $6.4 \pm 0.2 \ddagger$ & $5.7 \pm 0.2$ & $5.3 \pm 0.1 \S$ & $5.5 \pm 0.1 \ddagger$ & $5.0 \pm 0.2$ & $6.6 \pm 0.2$ & $7.0 \pm 0.2 \ddagger$ & $6.1 \pm 0.2$ \\
\hline Potassium (mmol/day) & $47 \pm 1$ & $49 \pm 1 \ddagger$ & $44 \pm 1$ & $41 \pm 1 \S$ & $42 \pm 1 \ddagger$ & $39 \pm 1$ & $51 \pm 1$ & $54 \pm 2 \ddagger$ & $47 \pm 2$ \\
\hline Na:K (molar ratio) & $2.4 \pm 0.05$ & $2.4 \pm 0.06$ & $2.3 \pm 0.06$ & $2.4 \pm 0.6$ & $2.4 \pm 0.8$ & $2.3 \pm 0.09$ & $2.4 \pm 0.6$ & $2.4 \pm 0.9$ & $2.4 \pm 0.6$ \\
\hline Creatinine (mmol/day) & $5.6 \pm 0.1$ & $5.8 \pm 0.2$ & $5.3 \pm 0.2$ & $4.3 \pm 0.1$ & $4.5 \pm 0.1$ & $4.1 \pm 0.1$ & $6.5 \pm 0.1$ & $6.8 \pm 0.2$ & $6.1 \pm 0.2$ \\
\hline Volume output (mL/day) & $866 \pm 22$ & $889 \pm 29$ & $838 \pm 26$ & $748 \pm 20$ & $748 \pm 21$ & $748 \pm 35$ & $953 \pm 26$ & $997 \pm 40$ & $902 \pm 34$ \\
\hline
\end{tabular}

*Linear regression with adjustment for school cluster was used to assess differences in the excretion of sodium, salt equivalent, potassium and $\mathrm{Na:K}$ molar ratio between subgroups.

†Additional adjustment for age, day of urine collection and BMI z-score did not alter results in any of the age or sex-subgroup analyses (data not shown). This was with the exception of urinary potassium excretion, which was no longer significantly higher in boys (fully adjusted model $\mathrm{p}=0.06$ ) within the age stratified sub-group analyses of 9-12 years.

$\ddagger<0.05$, significant difference between boys and girls.

$\S<0.05$, significant difference between age groups, that is, 4-8years versus 9-12 years.

(table 1). The mean molar ratio of sodium to potassium was 2.4, and this did not differ by sex or age group (table 1). Potassium excretion was significantly greater on non-school days $(49.0 \pm 1.5 \mathrm{mmol} /$ day $)$ compared with school days $(43.9 \pm 1.1 \mathrm{mmol} /$ day $)(\mathrm{p}=0.009)$, and this difference remained in adjusted models (data not shown). The difference in molar ratio of $\mathrm{Na}: \mathrm{K}$ across day types did not reach statistical significance, $2.3 \pm 0.1$ on school days versus $2.5 \pm 0.1$ on non-school days $(p=0.09)$, and this finding remained in adjusted models (data not shown).

\section{Twenty-four-hour urinary electrolyte excretion by socioeconomic status}

Urinary sodium excretion differed by socioeconomic background, low SES: $110 \pm 4 \mathrm{mmol} /$ day (salt $6.4 \pm 0.2 \mathrm{~g}$ / day), mid SES: $97 \pm 4 \mathrm{mmol} /$ day (salt $5.8 \pm 0.2 \mathrm{~g} /$ day) and high SES: $99 \pm 3 \mathrm{mmol} /$ day (salt $5.8 \pm 0.2 \mathrm{~g} /$ day), $\mathrm{p}=0.04$. Adjusted for age, sex and day of urine collection, those children from a low socioeconomic background excreted significantly more sodium than those of high socioeconomic background $(10 \mathrm{mmol} /$ day, salt $0.6 \mathrm{~g} /$ day $)$ and those of mid socioeconomic background $(12 \mathrm{mmol} /$ day, salt $0.7 \mathrm{~g} /$ day) (table 2). This difference remained with further adjustment for cooking and table salt use (data not shown). However, the addition of BMI z-score into the model reduced the association and only a significant difference in sodium excretion between the mid and low SES group remained (table 2). There were no significant socioeconomic differences in potassium excretion or the molar ratio of $\mathrm{Na}: \mathrm{K}$ (table 2 ).

\section{Discretionary salt use}

Two-thirds of parents reported adding salt during cooking either usually or sometimes (online supplementary figure $1)$. The child's self-reported use of table salt was greater (40\% add usually or sometimes) than when the parent reported the behaviour as a proxy for the child (28\% add usually or sometimes). Just over a third (36\%) of parents reported that they either usually or sometimes place a salt shaker on the table at meal times, and this behaviour was more common in parents with children aged 9-12 years ( $40.3 \%$ usually or sometimes) compared with those with children aged $4-8$ years $(29.9 \%$ usually or sometimes) (OR 1.58, 95\% CI 1.13 to 2.20, p<0.001). Similarly, parents of children aged 9-12 years were more likely to report that their child added salt at the table either usually or sometimes $(32.3 \%)$ compared with parents of younger children (22.4\%) (OR 1.7, 95\% CI 1.29 to 2.25, $\mathrm{p}=0.001$ ). There was no association between sex of the child or socioeconomic background and any of the four 'discretionary' salt use behaviours (data not shown).

\section{Food sources of sodium and potassium}

Seventy-nine percent of 24-hour dietary recalls were completed on a school day. Among children aged 8-12 years with a valid 24-hour dietary recall $(n=517)$, average (SD) intake of energy, salt and potassium was 8384 (2456) kJ/day, 6.0 (2.7) g/day and 2501 (909) $\mathrm{mg} /$ day, respectively. In the subsample of children aged 8-12 years who had a valid 24-hour dietary recall and a complete 24-hour urine collection $(n=464)$, salt intake measured by 24-hour dietary recall was $6.1 \pm 0.1 \mathrm{~g} /$ day versus $6.4 \pm 0.1 \mathrm{~g} /$ day measured by 24-hour urinary excretion $(\mathrm{p}=0.07)$. The type of day (school vs non-school) that salt intake was assessed on was an important factor with regards to observed differences in salt intake determined by each method. When the 24-hour dietary recall and 24-hour urine collection were completed on the same type of day, there was no difference in salt intake determined by each method (online supplementary table 2). Conversely, when the 24-hour dietary recall and 24-hour urine collection were completed on different day types, salt intake was consistently higher on non-school days. 


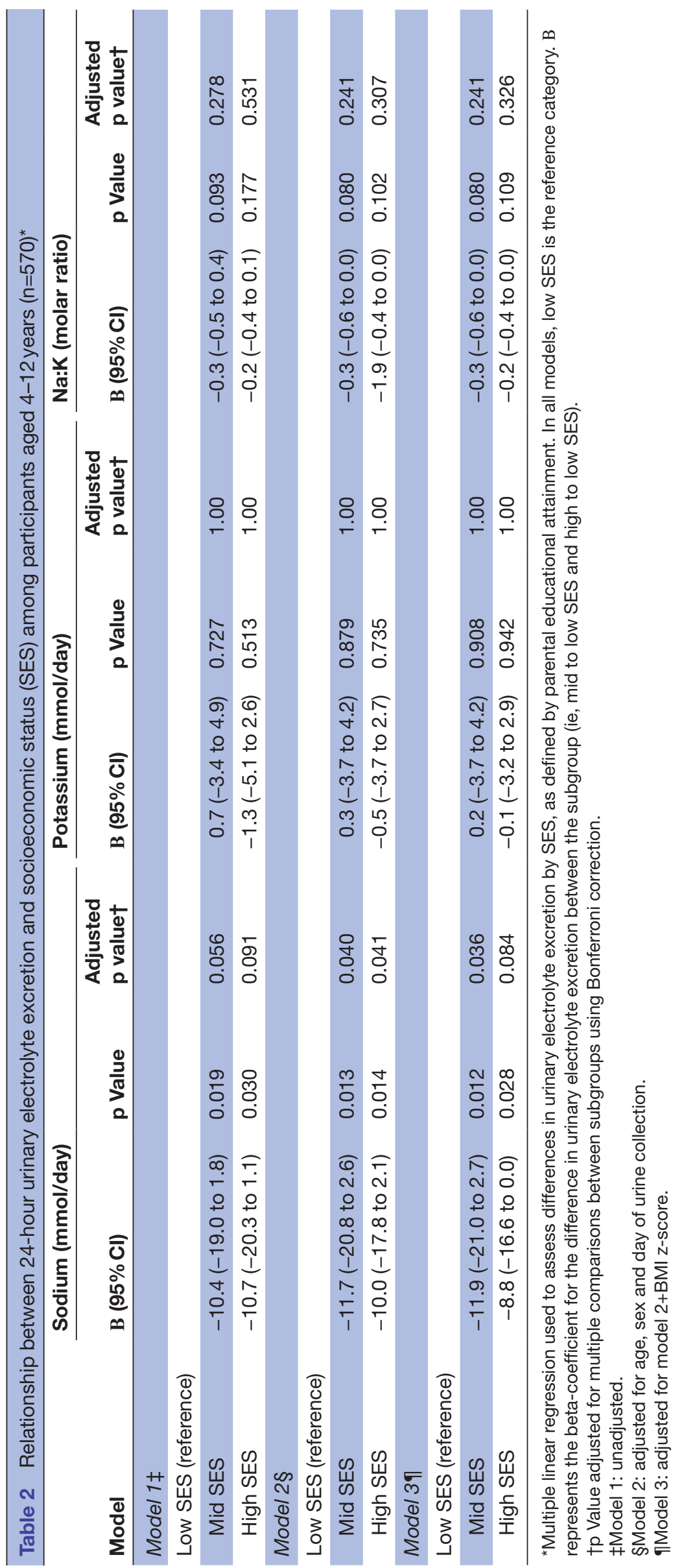




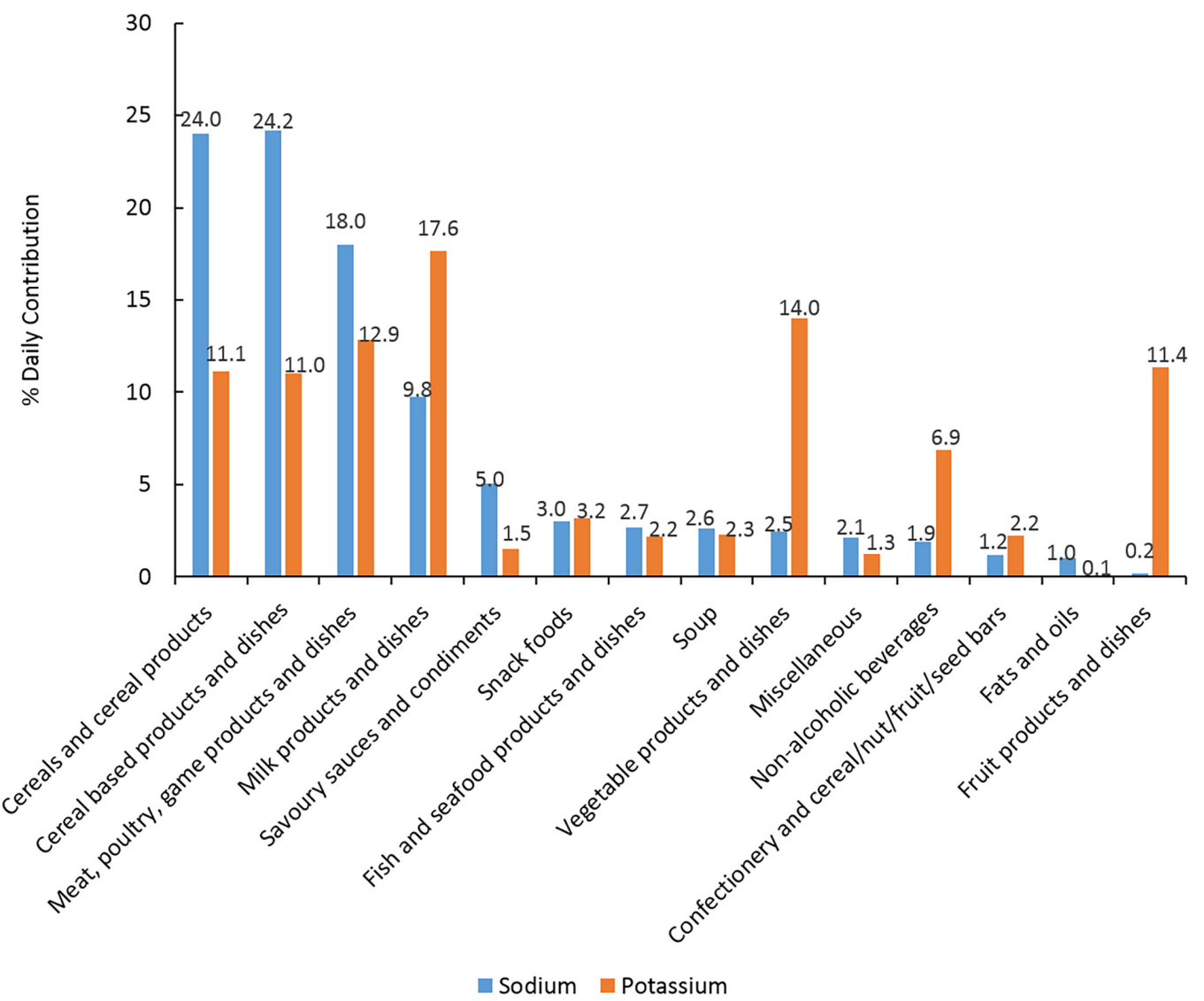

Figure 1 Daily contribution (\%) of sodium and potassium from major food groups among participants aged 8-12 years $(n=517)$, which includes major food groups provided $\geq 1 \%$ of daily intake of sodium or potassium. Food groups ranked in order of greatest contributor to sodium intake.

Figure 1 shows the contribution of sodium and potassium from major food groups. Almost half of all sodium consumed came from cereals and cereal-based products and dishes. Other important sources $(>10 \%)$ of sodium included meat, poultry and game products and dishes $(18.0 \%)$ and milk products and dishes $(9.8 \%)$. The major contributor to potassium intakes were milk products and dishes $(17.6 \%)$, other important sources included vegetable products and dishes $(14.0 \%)$, meat, poultry and game products and dishes $(12.9 \%)$, fruit products and dishes $(11.4 \%)$, cereal and cereal products $(11.1 \%)$ and cereal-based products and dishes $(11.0 \%)$.

Online supplementary table 3 lists the contribution of submajor food groups to sodium and potassium intakes. The top five sources of sodium were bread, mixed cereal-based dishes, processed meat, cakes, muffins, scones, cake-type desserts and cheese. Collectively, these food groups accounted for $43 \%$ of all sodium consumed. The top five sources of potassium were dairy milk, potatoes, fruit and vegetable juices/drinks, mixed cereal-based dishes and bread. Collectively, these food groups accounted for a third of all potassium consumed. When foods were grouped as either 'core' or 'discretionary', $59.9 \%$ of energy was derived from core foods and $40.1 \%$ of energy was derived from discretionary foods. Just over half of all sodium came from 'core' foods, whereas three quarters of potassium came from core foods (figure 2).
Online supplementary table 4 provides information on the food sources at the minor food group level.

\section{DISCUSSION}

Using an objective marker of salt intake, we found the average intake was $5.3 \mathrm{~g}$ /day among children aged 4-8 years and $6.6 \mathrm{~g} /$ day among children aged 9-12 years. This is $51 \%$ and $32 \%$ above the recommended UL for salt of $3.5 \mathrm{~g} /$ day and $5.0 \mathrm{~g} /$ day, respectively, for each age group. ${ }^{38}$ These findings are similar to those reported in the 2011-2012 National Nutrition and Physical Activity (NNPAS), measured via 24-hour dietary recall, which was $5.2 \mathrm{~g} /$ day and $6.3 \mathrm{~g} /$ day among children aged 4-8 years and $9-13$ years, respectively. ${ }^{20}$ Compared with recent international studies that have used 24-hour urinary excretion methods, the salt intake of our group is similar to those reported in children from Germany (salt median/ mean value range: $7-14$ years: $5.3-6.9 \mathrm{~g} /$ day),${ }^{40}$ lower than those reported in Italy (6-10 years: $5.3-7.3 \mathrm{~g} /$ day) ${ }^{22}$ Portugal (8-10 years: $6.1-7.5 \mathrm{~g} /$ day $)^{24}$ and Spain (7-11 years: $7.8 \mathrm{~g} /$ day $)^{21}$ and higher than those reported in the UK (4-10 years: $3.7-5.0 \mathrm{~g} /$ day) ${ }^{25}$ Lower intakes among British children, measured in 2008/2009-2011/2012 $2^{25}$ and $2007-2010,{ }^{23}$ are likely due to the comprehensive salt reduction initiatives, which have been under way in the UK since $2003{ }^{41}$ The UK campaign targeted consumer 


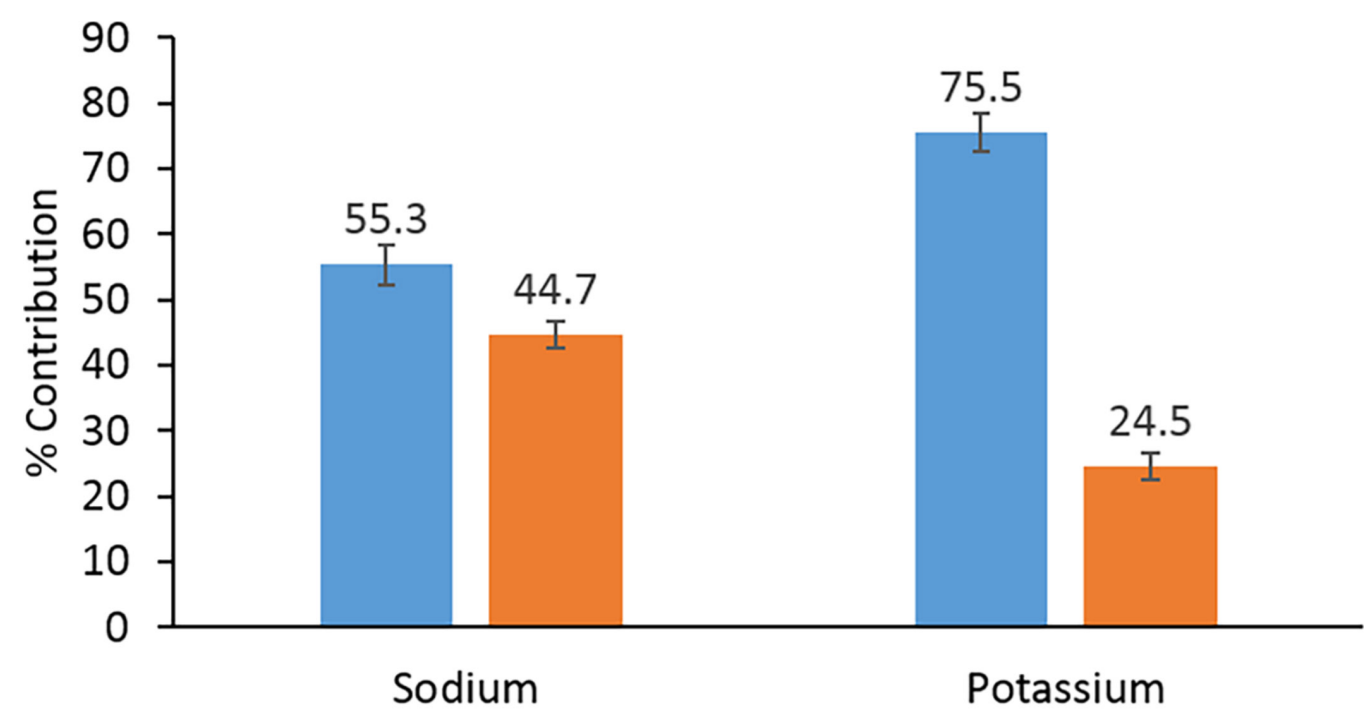

\section{Core foods $\square$ Discretionary foods}

Figure 2 Daily contribution (\%) of sodium and potassium from 'core' and 'discretionary' foods among participants aged $8-12$ years $(n=517)$. Data are mean \pm SE.

awareness of salt and voluntary product reformulation to remove salt from processed foods ${ }^{41}$ and resulted in $15 \%$ reduction in salt intake $(1.4 \mathrm{~g} /$ day, 24 -hour excretion) in adults between 2003 and 2011 . $^{42}$

Studies in adults and children report higher salt estimates derived from 24-hour urinary excretion, compared with 24-hour dietary recall methods. ${ }^{40} 43$ Reasons for differences are that dietary methods do not assess the use of table and cooking salt and there is the issue of under-reporting with dietary methods. ${ }^{32}$ Although salt intake measured by 24-hour urinary excretion (6.3 g/ day) in the current study was higher than that measured by 24-hour dietary recall $(6.1 \mathrm{~g} /$ day $)$, the difference did not reach statistical significance $(p=0.07)$. There was no difference in salt intake assessed between each method when both methods assessed salt intake on the same type of day (ie, school vs non-school).

Although most salt $(\sim 75 \%)$ consumed comes from processed foods, it is still important to consider the use of discretion, which accounts for $\sim 15 \%$ of daily intake. ${ }^{45}{ }^{46}$ Compared with national estimates, ${ }^{20}$ the frequency of reported salt added at the table and during cooking was greater within our study sample. We found that $40 \%$ of children aged 4-12 years self-reported that they added salt at the table either 'usually' or 'sometimes'. This compares to $10 \%$ and $24 \%$ of children aged 4-8 years and 9-13 years participating in the 2011-2012 NNPAS, who reported adding table salt either 'very often' or 'occasionally'. ${ }^{20}$ With respect to cooking salt, $60 \%$ of parents in our study reported that they added salt during cooking either 'usually' or 'sometimes'. This compares to $40 \%$ and $47 \%$ of parents of children aged $4-8$ years and 9-13 years, respectively, participating in the 20112012 NNPAS who reported adding cooking salt either 'very often' or 'occasionally'. ${ }^{20}$ The reasons for these differences are not clear, but may be due to slight variation in wording of questions between studies, a national versus convenience sample and the potential to provide more socially desirable responses in the national survey that was completed face to face versus our questionnaire that was completed by the parent at home.

Salt intake, assessed by 24-hour urine, was $1.0 \mathrm{~g}$ /day higher on non-school days compared with school days, and this is similar to our previous analysis of the national dietary survey, where salt intake was $0.5 \mathrm{~g} /$ day higher on non-school days in children aged $6-12$ years. ${ }^{47}$ This likely reflects an overall poorer quality diet on weekends ${ }^{47} 48$ characterised by greater consumption of 'discretionary' foods such as pizzas and burgers. ${ }^{47}$

In this study, we found some indication of socioeconomic disparities for salt intake but not for potassium intake or the molar ratio of Na:K. There was an overall trend for higher sodium intake from low to high SES groups, although the level of significance was attenuated after adjustment for BMI z-score and multiple comparisons. Previously within a national sample of children, we found that there was a $0.5 \mathrm{~g} /$ day difference in salt intake from food sources between children of low and high socioeconomic background. ${ }^{49}$ It appears that socioeconomic disparities in salt intake among children may be due to differences in food choices, ${ }^{49}$ rather than 'discretionary' salt use.

With respect to 24-hour urinary potassium excretion, our findings of $41 \mathrm{mmol} /$ day and $51 \mathrm{mmol} /$ day in children aged 4-8 years and 9-12 years, respectively, are similar to previous reports in children from Italy, ${ }^{22}$ Spain, ${ }^{21}$ Portugal $^{22}$ and the UK. ${ }^{23}$ A consistent finding across studies conducted in Western paediatric population groups is that children are consuming more sodium than potassium, leading to a high urinary Na:K molar 
ratio. ${ }^{2122} 24$ The average Na:K molar ratio was 2.4 in this study, well above the WHO's recommended ratio of $1 .^{50}$ Similar to studies in adults, ${ }^{51}$ we found 24-hour urinary potassium was $27 \%$ lower than that estimated from dietary recall as generally only $77 \%$ of dietary potassium is excreted in the urine. ${ }^{51}$

Our findings related to the food sources of sodium and potassium are consistent with those reported in the 2011-2012 NNPAS. ${ }^{20}$ In this survey, 39\% of energy was derived from discretionary foods (children aged 4-12 years), ${ }^{20}$ which is comparable to our finding of $40 \%$ of energy and $45 \%$ of sodium coming from discretionary foods. Strategies that seek to reduce discretionary food consumption would also facilitate reductions in salt intake. Core foods, which in accordance with the Australian Guide to Healthy Eating should form the basis of a healthy diet due to their overall beneficial nutrient profile, ${ }^{33}$ were found to provide a substantial amount of sodium $(55 \%)$ to the diet. This finding indicates the need to reduce the amount of sodium added to 'core' foods, such as bread (14.8\%) and cheese $(4.8 \%)$, both of which were within the top five sources of sodium. The large variation in sodium content seen within these products ${ }^{52-54}$ indicates the feasibility to reduce sodium. Setting sodium content targets for manufactured foods is a key element of salt reduction initiatives around the globe..$^{55}$ In 2009, the Australian Federal Government formed the Food and Health Dialogue, and during its 6-year working period, the group set voluntary sodium content targets for nine processed food categories. ${ }^{56}$ The success of three of the first targets set was demonstrated by Trevena et al who reported a reduction in the sodium content of Australian bread $(9 \%)$, breakfast cereals $(25 \%)$ and processed meats $(8 \%)$ between 2010 and 2013. ${ }^{57}$ In 2015, the Food and Health Dialogue was replaced with the Healthy Food Partnership,${ }^{56}$ which provides an opportunity to continue reformulation efforts related to sodium. ${ }^{56}$ In moving forward with salt reduction in Australia, lessons from the UK for successful salt reduction ${ }^{41}$ should be noted with a focus on setting progressive sodium content targets for a wide range of food categories and transparent monitoring mechanisms.

The main strength of the present study was an objective measure of sodium and potassium intake in a relatively large sample of children. Limitations of the study include the convenience sample and low response rate, which, although comparable with other studies requiring 24-hour urine collections, ${ }^{58}$ limit the generalisability of the findings to the wider population. Furthermore, it is possible that child participants were from families that were more health conscious than non-respondents. Despite efforts to reach all socioeconomic backgrounds via recruitment in both independent (ie, private) and government (ie, public) school sectors, close to two-thirds of children were from a high socioeconomic background. Compared with national estimates, our sample had fewer children who were overweight or obese; this may reflect different dietary patterns among our study participants compared with the general population. Our questions related to discretionary salt use are not validated as none are available for use in children. The response scale options are limited in their subjectiveness; for example, interpretation of 'usually' or 'sometimes' may be interpreted differently between participants. Finally, as we were limited to one 24-hour urine collection, we did not adjust the distribution of salt intake for within-person variation, which tends to lead to an underestimation of the number of children exceeding the UL for salt intake.

In conclusion, Victorian schoolchildren are consuming too much sodium and not enough potassium, which has important implications for cardiovascular health. Furthermore, there is some evidence to indicate that sodium intake is higher among those children of lower socioeconomic background. To improve the sodium and potassium profile of schoolchildren, product reformulation of lower salt core foods along with strategies, for example, pricing, policy and consumer education, that seek to reduce the consumption of discretionary foods are required.

Acknowledgements We acknowledge the Victorian Department of Early Childhood and Development for their support in allowing the study to be conducted within the government school sector. We thank all schools and children who participated in the study.

Contributors The authors' responsibilities were as follows: CAG, LJR, KJC, FJH and CAN designed research; CAG performed statistical analysis and wrote the manuscript and is guarantor of the paper; JRB was involved in data collection and cleaning and edited and reviewed the manuscript; KB managed and entered dietary data and edited and reviewed the manuscript; LJR, KJC, FJH and CAN helped with data interpretation, revision of manuscript and provided significant consultation. All authors have read and approved the final manuscript.

Funding This work was supported by a Heart Foundation of Australia Grantin-Aid (G10M5021) and a Helen MacPherson Smith Trust Fund Project Grant (6002). During this work, CAG was supported by a Heart Foundation Postgraduate Scholarship (PP08M4074) and a Heart Foundation of Australia Postdoctoral Fellowship (Award ID: 100155). During this work, JRB was supported by a National Heart Foundation of Australia Postgraduate Scholarship (Award ID: PP11M6172).

Competing interests All authors have completed the Unified Competing Interest form at www.icmje.org/coi_disclosure.pdf (available on request from the corresponding author) and declare: CAG received financial support in the form of a postgraduate scholarship and postdoctoral fellowship from the Heart Foundation, Australia, for the submitted work; JRB received financial support in the form of a postgraduate scholarship from the Heart Foundation, Australia. CAN has received research funds from Meat \& Livestock Australia; National Health and Medical Research Council, Wicking Foundation, National Heart Foundation, Australia, Helen MacPherson Smith Trust and Red Cross Blood Bank. These payments are unrelated to the submitted work. LJR has received research funds from Meat \& Livestock Australia. These payments are unrelated to the submitted work. CAG and CAN are members of World Action on Salt and Health (WASH) and Australian Division of World Action on Salt and Health (AWASH). FJH is a member of Consensus Action on Salt \& Health (CASH) and WASH. CASH, WASH and AWASH are non-profit charitable organisations and no authors receive any financial support. KJC and KB had no support from any organisation for the submitted work and no other relationships or activities that could appear to have influenced the submitted work.

Patient consent Guardian consent obtained.

Ethics approval Deakin University Human Research Ethics Committee.

Provenance and peer review Not commissioned; externally peer reviewed.

Data sharing statement Data and materials are stored at the Institute for Physical Activity and Nutrition, Deakin University. The data will not be shared as this was not approved by the Deakin University Human Ethics Advisory Group or study participants. 
Open Access This is an Open Access article distributed in accordance with the Creative Commons Attribution Non Commercial (CC BY-NC 4.0) license, which permits others to distribute, remix, adapt, build upon this work non-commercially, and license their derivative works on different terms, provided the original work is properly cited and the use is non-commercial. See: http://creativecommons.org/ licenses/by-nc/4.0/

(c) Article author(s) (or their employer(s) unless otherwise stated in the text of the article) 2017. All rights reserved. No commercial use is permitted unless otherwise expressly granted.

\section{REFERENCES}

1. Aburto NJ, Hanson S, Gutierrez H, et al. Effect of increased potassium intake on cardiovascular risk factors and disease: systematic review and meta-analyses. BMJ 2013;346:f1378.

2. Aburto NJ, Ziolkovska A, Hooper L, et al. Effect of lower sodium intake on health: systematic review and meta-analyses. BMJ 2013;346:f1326.

3. Aaron KJ, Sanders PW. Role of dietary salt and potassium intake in cardiovascular health and disease: a review of the evidence. Mayo Clin Proc 2013;88:987-95

4. Strazzullo P, D'Elia L, Kandala NB, et al. Salt intake, stroke, and cardiovascular disease: meta-analysis of prospective studies. BMJ 2009;339:b4567.

5. He FJ, MacGregor GA. Importance of salt in determining blood pressure in children: meta-analysis of controlled trials. Hypertension 2006;48:861-9.

6. Buendia JR, Bradlee ML, Daniels SR, et al. Longitudinal effects of dietary sodium and potassium on blood pressure in adolescent girls. JAMA Pediatr 2015;169:560-8.

7. Shi L, Krupp D, Remer T, Salt RT. Salt, fruit and vegetable consumption and blood pressure development: a longitudina investigation in healthy children. Br J Nutr 2014;111:662-71.

8. Geleijnse JM, Grobbee DE, Hofman A. Sodium and potassium intake and blood pressure change in childhood. BMJ 1990;300:899-902.

9. Chen X, Wang Y. Tracking of blood pressure from childhood to adulthood: a systematic review and meta-regression analysis. Circulation 2008;117:3171-80.

10. Tirosh A, Afek A, Rudich A, et al. Progression of normotensive adolescents to hypertensive adults: a study of 26,980 teenagers. Hypertension 2010;56:203-9.

11. Lai CC, Sun D, Cen R, et al. Impact of long-term burden of excessive adiposity and elevated blood pressure from childhood on adulthood left ventricular remodeling patterns: the Bogalusa Heart Study. J Am Coll Cardiol 2014;64:1580-7.

12. Li S, Chen W, Srinivasan SR, et al. Childhood blood pressure as a predictor of arterial stiffness in young adults: the Bogalusa Heart Study. Hypertension 2004;43:541-6.

13. Appel LJ, Lichtenstein AH, Callahan EA, et al. Reducing sodium intake in children: a public health investment. J Clin Hypertens 2015;17:657-62.

14. Stein LJ, Cowart BJ, Beauchamp GK. The development of salty taste acceptance is related to dietary experience in human infants: a prospective study. Am J Clin Nutr 2012;95:123-9.

15. Webster J, Trieu K, Dunford E, et al. Salt reduction in Australia: from advocacy to action. Cardiovasc Diagn Ther 2015;5:207-18.

16. Webster J, Bolam B. The state of salt: how state-based initiatives can drive national action on salt reduction in Australia. Aust N Z J Public Health 2016;40:203.

17. World Health Organization. 2010. Strategies to monitor and evaluate population sodium consumption and sources of sodium in the diet. Report of a joint technical meeting convened by WHO and the Government of Canada. Canada: WHO.

18. Grimes CA, Riddell LJ, Campbell KJ, et al. Dietary salt intake assessed by $24 \mathrm{~h}$ urinary sodium excretion in Australian schoolchildren aged 5-13 years. Public Health Nutr 2013;16:1789-95.

19. Miles JM, Miles TS. Effect of processed foods on the salt intake of preschool children: a pilot study. Med J Aust 1982;2:23-5.

20. Australian Bureau of Statistics. 4364.0.55.007-Australian Health Survey: Nutrition First Results-Foods and Nutrients, 2011-12. http://www.abs.gov.au/AUSSTATS/abs@.nsf/DetailsPage/4364.0.55. 0072011-12?OpenDocument (accessed 12 Jun 2014).

21. Aparicio A, Rodríguez-Rodríguez E, Cuadrado-Soto E, et al. Estimation of salt intake assessed by urinary excretion of sodium over $24 \mathrm{~h}$ in Spanish subjects aged 7-11 years. Eur J Nutr 2017;56:171-8.
22. Campanozzi A, Avallone S, Barbato A, et al. High sodium and low potassium intake among Italian children: relationship with age, body mass and blood pressure. PLoS One 2015;10:e0121183.

23. Marrero NM, He FJ, Whincup $P$, et al. Salt intake of children and adolescents in South London: consumption levels and dietary sources. Hypertension 2014;63:1026-32.

24. Oliveira AC, Padrão $P$, Moreira $A$, et al. Potassium urinary excretion and dietary intake: a cross-sectional analysis in 8-10 year-old children. BMC Pediatr 2015;15:60.

25. England $\mathrm{PH}$, Diet N, Survey N. Results from Years 1-4 (combined) of the Rolling Programme (2008/2009-2011/12). London, UK: Public Health England, 2014.

26. Grimes CA, Baxter JR, Campbell KJ, et al. Cross-sectional study of 24-hour urinary electrolyte excretion and associated health outcomes in a convenience sample of Australian primary schoolchildren: the Salt and Other Nutrients in Children (SONIC) Study Protocol. JMIR Res Protoc 2015;4:e7.

27. Sichert-Hellert W, Kersting M, Schöch G. Underreporting of energy intake in 1 to 18 year old German children and adolescents. Z Ernahrungswiss 1998;37:242-51.

28. Torun B, Davies PS, Livingstone MB, et al. Energy requirements and dietary energy recommendations for children and adolescents 1 to 18 years old. Eur J Clin Nutr 1996;50:S37-80.

29. Black AE. Critical evaluation of energy intake using the Goldberg cut-off for energy intake: basal metabolic rate. A practical guide to its calculation, use and limitations. Int J Obes Relat Metab Disord 2000;24:1119-30.

30. Food Standards Australia and New Zealand. AUSNUT 2011-13 Food Nutrient Database 486 File. 2011-13 http://www.foodstandards. gov.au/science/monitoringnutrients/ausnut/Pages/default.aspx (accessed Jul 15 2016).

31. Grimes CA, Riddell LJ, Campbell KJ, et al. 24-h urinary sodium excretion is associated with obesity in a cross-sectional sample of Australian schoolchildren. Br J Nutr 2016;115:1071-9.

32. Australian Bureau of Statistics. 4363.0.55.001-Australian Health Survey: Users' Guide, 2011-13 Australian Health SurveyDiscretionary Food List. http://www.abs.gov.au/AUSSTATS/abs@.nsf/ DetailsPage/4363.0.55.0012011-13?OpenDocument (accessed Jul 15 2016).

33. National Health and Medical Research Council. Australian Guide to Healthy Eating. https://www.eatforhealth.gov.au/guidelines/ australian-guide-healthy-eating (accessed $15 \mathrm{Jul} 2016$ ).

34. Flegal KM, Cole TJ. Construction of LMS parameters for the Centers for Disease Control and Prevention 2000 growth charts. Natl Health Stat Report 2013;63:1-3.

35. Kuczmarski RJ, Ogden CL, Guo SS, et al. 2000 CDC Growth Charts for the United States: methods and development. Vital Health Stat 11 2002;2002:1-190.

36. Cole TJ, Bellizzi MC, Flegal KM, et al. Establishing a standard definition for child overweight and obesity worldwide: international survey. BMJ 2000;320:1240-6.

37. Cole TJ, Flegal KM, Nicholls D, et al. Body mass index cut offs to define thinness in children and adolescents: international survey. BMJ 2007;335:194-7.

38. National Health and Medical Research Council. Nutrient reference values for Australia and New Zealand. Canberra: Australian Government. Department of Health and Ageing, 2006.

39. Krebs-Smith SM, Kott PS, Guenther PM. Mean proportion and population proportion: two answers to the same question? J Am Diet Assoc 1989;89:667-72.

40. Libuda L, Kersting M, Alexy U. Consumption of dietary salt measured by urinary sodium excretion and its association with body weight status in healthy children and adolescents. Public Health Nutr 2012;15:433-41.

41. He FJ, Brinsden HC, MacGregor GA. Salt reduction in the United Kingdom: a successful experiment in public health. J Hum Hypertens 2014;28:345-52.

42. He FJ, Pombo-Rodrigues S, Macgregor GA. Salt reduction in England from 2003 to 2011: its relationship to blood pressure, stroke and ischaemic heart disease mortality. BMJ Open 2014:4:e004549.

43. Espeland MA, Kumanyika S, Wilson AC, et al. Statistical issues in analyzing 24-hour dietary recall and 24-hour urine collection data for sodium and potassium intakes. Am J Epidemiol 2001;153:996-1006.

44. Loria CM, Obarzanek E, Ernst ND. Choose and prepare foods with less salt: dietary advice for all Americans. J Nutr 2001;131:536S-551S.

45. James WP, Ralph A, Sanchez-Castillo CP. The dominance of salt in manufactured food in the sodium intake of affluent societies. Lancet 1987;1:426-9.

46. Mattes RD, Donnelly D. Relative contributions of dietary sodium sources. J Am Coll Nutr 1991;10:383-93. 
47. Grimes CA, Riddell LJ, Nowson CA. Nutrient and core and noncore food intake of Australian schoolchildren differs on school days compared to non-school days. Appetite 2014;83:104-11.

48. Rothausen BW, Matthiessen J, Hoppe C, et al. Differences in Danish children's diet quality on weekdays v. weekend days. Public Health Nutr 2012;15:1653-60.

49. Grimes CA, Campbell KJ, Riddell LJ, et al. Is socioeconomic status associated with dietary sodium intake in Australian children? A cross-sectional study. BMJ Open 2013;3:e002106.

50. World Health Organization. Guideline: Sodium intake for adults and children. Geneva: World Health Organization (WHO), 2012.

51. Tasevska N, Runswick SA, Bingham SA. Urinary potassium is as reliable as urinary nitrogen for use as a recovery biomarker in dietary studies of free living individuals. J Nutr 2006;136:1334-40.

52. Brinsden HC, He FJ, Jenner KH, et al. Surveys of the salt content in UK bread: progress made and further reductions possible. BMJ Open 2013;3:e002936.
53. Hashem KM, He FJ, Jenner KH, et al. Cross-sectional survey of salt content in cheese: a major contributor to salt intake in the UK. BMJ Open 2014;4:e005051.

54. Webster JL, Dunford EK, Neal BC. A systematic survey of the sodium contents of processed foods. Am J Clin Nutr 2010;91:413-20.

55. Trieu K, Neal B, Hawkes C, et al. Salt reduction initiatives around the world-a systematic review of progress towards the global target. PLoS One 2015;10:e0130247.

56. Jones A, Magnusson R, Swinburn B, et al. Designing a healthy food partnership: lessons from the Australian Food and Health Dialogue. BMC Public Health 2016;16:651.

57. Trevena $\mathrm{H}$, Neal B, Dunford E, et al. An evaluation of the effects of the Australian Food and Health Dialogue targets on the sodium content of bread, breakfast cereals and processed meats. Nutrients 2014;6:3802-17.

58. Hawkes C, Webster J. National approaches to monitoring population salt intake: a trade-off between accuracy and practicality? PLoS One 2012;7:e46727. 